\title{
Synthesis of $\mathrm{ZnS}: \mathrm{Mn}^{2+}$ and $\mathrm{ZnS}: \mathrm{Mn}^{2+} / \mathrm{ZnS}$ core-shell nanoparticles using poly(methyl methacrylate)
}

\author{
G. Murugadoss
}

Received: 9 June 2012/ Accepted: 5 September 2012/Published online: 18 September 2012

(C) The Author(s) 2012. This article is published with open access at Springerlink.com

\begin{abstract}
The water-soluble and high-quality $\mathrm{ZnS}: \mathrm{Mn}^{2+}$ / $\mathrm{ZnS}$ core-shell nanoparticles were synthesized by chemical precipitation method in an air atmosphere. The poly(methyl methacrylate) (PMMA) was used as a surfactant. Structural, morphology and optical properties were characterized by $\mathrm{X}$-ray diffraction (XRD), transmission electron microscopy (TEM), UV-visible absorption and photoluminescence spectrometer, respectively. The obtained particles were highly crystalline and monodisperse with an average particle size ranging from 3 to $6 \mathrm{~nm}$. A typical plant-(leafs, stem, and roots) like structures were obtained by passivation of PMMA on $\mathrm{ZnS}: \mathrm{Mn}^{2+}$ surface. The presence of $\mathrm{ZnS}$ shell on $\mathrm{ZnS}: \mathrm{Mn}^{2+}$ surface was confirmed by XRD, TEM and EPR studies. Well-defined and very narrow size distributed core-shell nanoparticles were prepared by capping with PMMA molecules on $\mathrm{ZnS}: \mathrm{Mn}^{2+} / \mathrm{ZnS}$ core-shell nanoparticles. The PMMA layer on $\mathrm{ZnS}: \mathrm{Mn}^{2+} / \mathrm{ZnS}$ was also clearly identified in the TEM images.
\end{abstract}

Keywords Core-shell nanoparticles - Surface defect . Monodisperse · PMMA · Luminescence

\section{Introduction}

Nanometer-sized semiconductor particles which are in strong quantum confinement regime have aroused considerable interest because of their unique and large sizedependant properties. Recently, attempts have been made not only to elaborate nanocrystals with well-defined

G. Murugadoss ( $\square)$

Centre for Nanoscience and Technology, Anna University,

Chennai 600 025, Tamilnadu, India

e-mail: murugadoss_g@yahoo.com structural properties such as mean size, chemical composition, crystallography, morphology, but also to manipulate their surfaces. The surface contains a large number of atoms so that electronic states created at the surfaces may be important and hence it strongly influences the physical properties of such nanostructures. One of the methods for controlling the surface states consists of the coating of nanocrystals by a shell of a different species (Tian et al. 1996; Kortan et al. 1990; Hoener et al. 1992; Mews et al. 1994). Even though a number of methods have been employed to synthesize $\mathrm{ZnS}: \mathrm{Mn}^{2+}$ nanoparticles ( $\mathrm{Lu}$ et al. 2009; Cao et al. 2009; Keshari and Pandey 2009; Hajisalem et al. 2009; Wang et al. 2008), low luminescence efficiency caused by surface states is still a common problem for these nanoparticles. Therefore, the surface passivation of $\mathrm{ZnS}: \mathrm{Mn}^{2+}$ nanoparticles is an important issue for improving the luminescence efficiency. To get a better passivation, inorganically passivated (or core/shell structured) $\mathrm{ZnS}: \mathrm{Mn}^{2+}$ nanoparticles have been developed and shown dramatically enhanced properties. For example, improved fluorescence properties have been observed in several core/shell nanoparticles, such as $\mathrm{ZnS}: \mathrm{Mn} / \mathrm{SiO}_{2}$ (Mews et al. 1994; Nien et al. 2008), ZnS:Mn/ZnO (Jiang et al. 2008), and $\mathrm{ZnS}: \mathrm{Mn} / \mathrm{Zn}(\mathrm{OH})_{2}$ (Jiang et al. 2007). Owing to a variety of applications of these core/shell nanocomposites as compared to their individual singlecomponent nanostructures, such as in solar photovoltaic devices, chemical/biological sensors, light-emitting diodes, and optical switches (Santra et al. 2005; Kim and Osterloh 2005; Ipe and Niemeyer 2006; Yang et al. 2006; Ouyang et al. 2007; Deka et al. 2009), it has led to the fabrication and study of the metal and semiconductor-based core/shell nanostructures.

Especially, the $\mathrm{ZnS}: \mathrm{Mn}^{2+} / \mathrm{ZnS}$ core/shell nanoparticles have exhibited much higher luminescence efficiency than 
uncoated ones due to the effective elimination of surface defects and a good match between core $\left(\mathrm{ZnS}: \mathrm{Mn}^{2+}\right)$ and shell (ZnS) lattice constants (Cao et al. 2002). Many methods have been explored for the preparation of $\mathrm{ZnS}: \mathrm{Mn}^{2+} / \mathrm{ZnS}$ core/shell nanoparticles, such as reverse micelle route (Cao et al. 2002), microwave-assisted growth (Jian et al. 2007), precipitation reaction method (Jiang et al. 2009), and nucleation-doping strategy (Xiao and Xiao 2008). However, these synthesized nanoparticles usually suffer from poor crystallinity, particle agglomeration, less size controllability, and poor water-solubility, which significantly hinder their potential applications. In addition, the luminescence lifetime of $\mathrm{ZnS}: \mathrm{Mn}^{2+}$ nanoparticles is $1 \mathrm{~ms}$; such a long lifetime makes the luminescence from the nanoparticles readily distinguishable from the background luminescence. Therefore, $\mathrm{ZnS}: \mathrm{Mn}^{2+}$ nanoparticles could be recommended as potential candidates for fluorescent labeling agents, especially in biology (Zhuang et al. 2003). To be a suitable biological labeling agent, the nanoparticles are required to have not only high luminescence efficiency but also good watersolubility.

In this paper, a novel two-step method has been developed to synthesize water soluble $\mathrm{ZnS}: \mathrm{Mn}^{2+} / \mathrm{ZnS}$ core/shell nanoparticles which are highly crystalline and nearly monodisperse. An interesting morphology is observed for poly(methyl methacrylate) (PMMA) capped $\mathrm{ZnS}: \mathrm{Mn}^{2+}$ and $\mathrm{ZnS}: \mathrm{Mn}^{2+} / \mathrm{ZnS}$ nanoparticles stabilized in water/ chloroform/ethanol matrix. Furthermore, the $\mathrm{ZnS}: \mathrm{Mn}^{2+}$ / $\mathrm{ZnS}$ core/shell nanoparticles are water-soluble and exhibit improved fluorescence property which indicates their potential applications for biological labeling as well as optical devices.

\section{Experimental}

\section{Materials}

To synthesize uncapped and surfactant capped $\mathrm{ZnS}: \mathrm{Mn}^{2+}$, the following materials were used. Zinc acetate $(\mathrm{Zn}$ $\left.\left(\mathrm{CH}_{3} \mathrm{COO}\right)_{2} \cdot 2 \mathrm{H}_{2} \mathrm{O}\right)$, manganese chloride $\left(\mathrm{MnCl}_{2} \cdot 4 \mathrm{H}_{2} \mathrm{O}\right)$, and sodium sulfide $\left(\mathrm{Na}_{2} \mathrm{~S} \cdot \mathrm{xH}_{2} \mathrm{O}\right)$ (Nice Chemical company, $99 \%$ ). Poly(methyl methacrylate) (MW 120,000; Aldrich $99 \%$ ). All the glassware used in this experimental work were acid washed. The chemical reagents used were analytical reagent grade without further purification. Ultrapure water was used for all dilution and sample preparation.

Synthesis of uncapped and PMMA capped $\mathrm{ZnS}: \mathrm{Mn}^{2+}$ nanoparticles

The uncapped and PMMA capped $\mathrm{ZnS}: \mathrm{Mn}^{2+}$ nanoparticles were synthesized in deionized water at ambient condition.
In a typical experiment, $5.48 \mathrm{~g} \quad(0.5 \mathrm{M})$ of $\mathrm{Zn}$ $\left(\mathrm{CH}_{3} \mathrm{COO}\right)_{2} \cdot 2 \mathrm{H}_{2} \mathrm{O}$ in $50 \mathrm{ml}$ aqueous and $4 \%$ of $\mathrm{MnCl}_{2} \cdot 4 \mathrm{H}_{2} \mathrm{O}$ in $25 \mathrm{ml}$ aqueous were mixed. The mixture was stirred magnetically and heated at $80{ }^{\circ} \mathrm{C}$ until a homogeneous solution was obtained. Then, $50 \mathrm{ml}$ of PMMA $(0.5 \mathrm{~g})$ solution was prepared in water-chloroform mixture (equal volume) and added to the above solution. Then, $2.75 \mathrm{~g}(0.5 \mathrm{M})$ of $50 \mathrm{ml} \mathrm{Na} \mathrm{Na}_{2} \mathrm{~S}$ was added drop by drop. After the $\mathrm{Na}_{2} \mathrm{~S}$ injection a white voluminous precipitate was appeared. Later, it was slowly dissolved under the formation of $\mathrm{ZnS}: \mathrm{Mn}^{2+}$ nanoparticles during the stirring process. The derived dispersions looked transparent and were purified by deionized water and acetone for several times to remove impurities. The products were dried in hot air oven at $120{ }^{\circ} \mathrm{C}$ for $2 \mathrm{~h}$. The uncapped (without PMMA) $\mathrm{ZnS}: \mathrm{Mn}^{2+}$ nanoparticles were also synthesized by following the same procedure.

Synthesis of uncapped and PMMA capped ZnS: $\mathrm{Mn}^{2+}$ /

ZnS core-shell nanoparticles

$\mathrm{ZnS}: \mathrm{Mn}^{2+} / \mathrm{ZnS}$ core-shell nanoparticles capped with PMMA were synthesized at ambient condition. The procedure is as follows, $50 \mathrm{ml}$ of $0.5 \mathrm{M} \mathrm{Zn}\left(\mathrm{CH}_{3} \mathrm{COO}\right)_{2} \cdot 2 \mathrm{H}_{2} \mathrm{O}$, $25 \mathrm{ml}$ of $0.4 \% \mathrm{MnCl}_{2} \cdot 4 \mathrm{H}_{2} \mathrm{O}$ and $50 \mathrm{ml}$ of freshly prepared $0.5 \mathrm{~g}$ of PMMA solution (water-chloroform mixture) were added under continuous stirring at $80{ }^{\circ} \mathrm{C}$. After increasing the $\mathrm{pH}$ value of the solution to 8.5 using $\mathrm{NaOH}, 50 \mathrm{ml}$ of freshly prepared $0.5 \mathrm{M} \mathrm{Na}_{2} \mathrm{~S}$ was quickly injected into the above solution during stirring. After stirring for $30 \mathrm{~min}$, $25 \mathrm{ml}$ of $0.1 \mathrm{M} \mathrm{Zn}\left(\mathrm{CH}_{3} \mathrm{COO}\right)_{2} \cdot 2 \mathrm{H}_{2} \mathrm{O}$ was injected into the reaction solution, and finally, it was stirred for another 30 min. The uncapped $\mathrm{ZnS}: \mathrm{Mn}^{2+} / \mathrm{ZnS}$ core/shell nanoparticles were synthesized by the same procedure in the absence of PMMA solution.

\section{Characterization}

The X-ray diffraction (XRD) patterns of the powdered samples $\left(\mathrm{ZnS}: \mathrm{Mn}^{2+}, \mathrm{ZnS}: \mathrm{Mn}^{2+} / \mathrm{PMMA}, \mathrm{ZnS}: \mathrm{Mn}^{2+} / \mathrm{ZnS}\right.$, and $\left.\mathrm{ZnS}: \mathrm{Mn}^{2+} / \mathrm{ZnS} / \mathrm{PMMA}\right)$ were recorded using an X'pert PRO diffractometer with $\mathrm{Cu} \mathrm{K}_{\alpha}$ radiation $(\lambda=$ $1.54060 \AA$ ) at room temperature. The crystallite size was estimated using the Scherer equation $D=(0.9 \lambda) /(\beta \cos \theta)$ at the full width at half maximum (FWHM) of the major XRD peak. The size and morphology of the nanoparticles were determined using transmission electron microscopy (TEM) (HITACHI-7650; $100 \mathrm{kV}$ ) images. Particle size was measured using a Nanotrac (FLEX 10.5.2) particle size analyzer. The optical absorption spectra of the particles in deionized water were recorded using a UV-1650PC SHIMADZU spectrometer. Fluorescence measurements were performed on a RF-5301PC spectrophotometer. The 


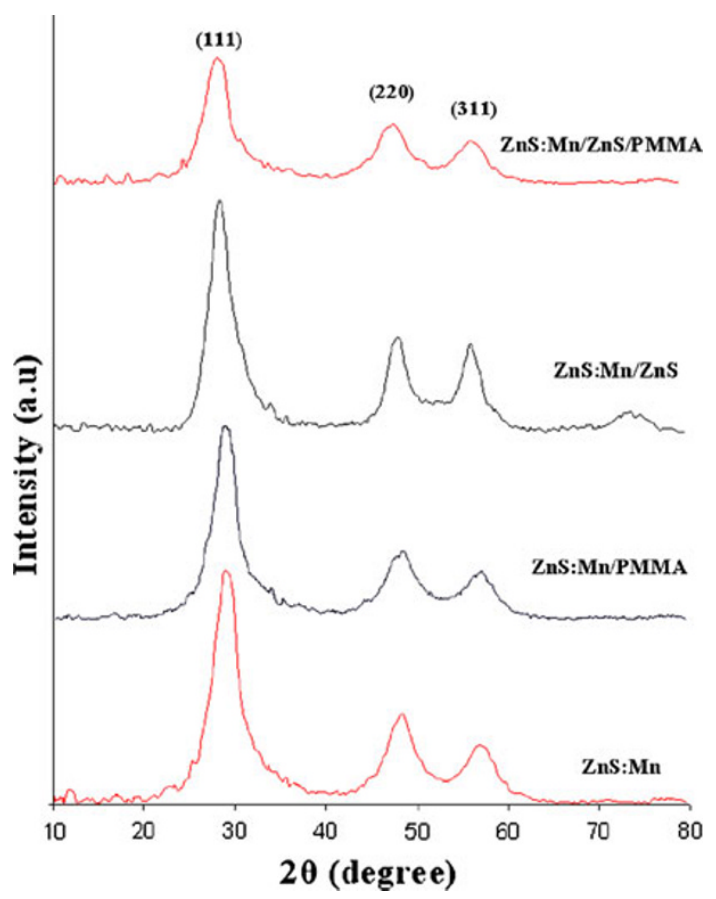

Fig. 1 X-ray diffraction pattern of uncoated and $\mathrm{ZnS}$ coated $\mathrm{ZnS}: \mathrm{Mn}^{2+}(4 \%)$ core-shell nanoparticles

thermal analysis was carried out with an SDT Q600 20 thermometer. Electron paramagnetic resonance (EPR) spectra of the $\mathrm{ZnS}: \mathrm{Mn}^{2+}$ and $\mathrm{ZnS}: \mathrm{Mn}^{2+} / \mathrm{ZnS}$ powder were measured on an EPR spectrometer (Bruker EMX Plus) at room temperature.

\section{Results and discussion}

Structure and morphology

Crystallinity, size and phase of particles were characterized by XRD analysis. The recorded patterns for all the samples are shown in Fig. 1. Peak positions of the synthesized powder indicate the formation of zinc blende crystal structure with three most preferred orientations (111), (220), and (311). There is no observable impurity phase in the spectra, which indicates the formation of pure cubic phase of $\mathrm{ZnS}$ only. The broadening of the diffraction peaks divulges the formation of nanosized particles. The average nanocrystallites size is calculated from FWHM of XRD peaks using Debye-Scherrer's formula (Cullity 1978)

$D=0.9 \lambda /(\beta \cos \theta)$

where $\lambda$ is the wavelength of incident X-ray (1.54 $\AA$ ) and $\theta$ is the Bragg's angle and $\beta$ is the FWHM. It is clearly noted that the FWHM of the (111) diffraction peak of the samples are very broad, which indicates that the samples have tiny size particles. From the calculations, the average diameters for uncapped and PMMA capped $\mathrm{ZnS}: \mathrm{Mn}^{2+}$ particles are 4.2 and $3.2 \mathrm{~nm}$, respectively. For uncapped and PMMA capped $\mathrm{ZnS}: \mathrm{Mn}^{2+} \mathrm{ZnS}$ core-shell nanoparticles, the average particles sizes are 5.4 and $5.0 \mathrm{~nm}$, respectively. The interplanar spacing $\left(d_{111}\right)$ is about $3.096-3.128 \AA$ for undoped $\mathrm{ZnS}$ (not shown) and $\mathrm{ZnS}: \mathrm{Mn}^{2+}$ (4\%) samples, respectively. The substitution of the $\mathrm{Zn}^{2+}$ ions $\left(r_{\mathrm{Zn}}^{2+}=\right.$ $0.78 \AA$ ) with the higher radius $\mathrm{Mn}^{2+}$ ions $\left(r_{\mathrm{Mn}}^{2+}=0.83 \AA\right)$ results in a small increase $(\sim 1 \%)$ in lattice constant of $\mathrm{ZnS}$. This increased lattice constant gives strong evidence for the incorporation of dopant ion into the host matrix. However, the observed interplanar spacing $\left(d_{111}\right)$ of the $\mathrm{ZnS}: \mathrm{Mn}^{2+} / \mathrm{ZnS}$ core-shell is similar to that of $\mathrm{ZnS}: \mathrm{Mn}^{2+}$ nanoparticles. Moreover, $\mathrm{ZnS}: \mathrm{Mn}^{2+} / \mathrm{ZnS}$ core-shell size is significantly increased than $\mathrm{ZnS}: \mathrm{Mn}^{2+}$ nanoparticles. It may be due to the presence of a thin shell $(\mathrm{ZnS})$ on the surface of the $\mathrm{ZnS}: \mathrm{Mn}^{2+}$ nanoparticles. However, the intensity of uncoated $\mathrm{ZnS}: \mathrm{Mn}^{2+}$ is stronger than the $\mathrm{ZnS}: \mathrm{Mn}^{2+} / \mathrm{ZnS}$ core-shell particles. This may be due to control the growth (particles) rate by $\mathrm{ZnS}$ on $\mathrm{ZnS}: \mathrm{Mn}^{2+}$ surface. Besides, the structure of the particles has no change due to the addition of surfactant in the solution. It reveals that the surfactant molecules did not react or substitute into the $\mathrm{ZnS}: \mathrm{Mn}^{2+}$ lattice site.

The morphology of the nanoparticles and especially the growth of the shell are further characterized by TEM. Figure 2 gives the TEM images of uncapped (Fig. 2a, b) and PMMA capped (Fig. 2c, d) $\mathrm{ZnS}: \mathrm{Mn}^{2+}$ nanoparticles with different magnifications. As could be seen, the particle sizes were estimated to be about $4.2-3.3 \mathrm{~nm}$ range with spherical shape. This result is found to be good agreement with XRD result. As shown in Fig. 2a, b the synthesized particles are considerably aggregated, which may be due to the absence of organic or inorganic surfactant on the particles surface.

Figure 2c shows an interesting morphology structure of $\mathrm{ZnS}: \mathrm{Mn}^{2+} / \mathrm{PMMA}$ nanoparticles. The dark parts in the corners show the structure like trunk of tree. In addition, the growths of the particles seem as some leafs-and stemlike structures. Also, it could be seen in some portion of the image that leafs are directly branched from the root (Fig. 2c). Thus, the assembling of very small spherical particles appears as root structure with micrometer leafs. These structures may be due to the assembling of $\mathrm{ZnS}: \mathrm{Mn}^{2+}$ nanoparticles by carboxylic PMMA. Figure 2d, e shows the TEM micrographs of PMMA-coated $\mathrm{ZnS}: \mathrm{Mn}^{2+}$ nanoparticles with higher magnifications. It clearly illustrates that the $\mathrm{ZnS}: \mathrm{Mn}^{2+} / \mathrm{PMMA}$ nanoparticles are highly monodispersed with spherical shape. Remarkably, the $\mathrm{ZnS}: \mathrm{Mn}^{2+}$ nanoparticles passivated with PMMA (Fig. 2c-e) are very small as compared with that of uncapped (Fig. 2a, b) particles. Furthermore, the particles have very narrow size distribution when compared with uncapped particles. In addition, the particles intensity (number of the particles 
Fig. 2 TEM images of uncapped (a, b) and PMMA capped (c-e) ZnS:Mn ${ }^{2+}$ nanoparticles with different magnifications

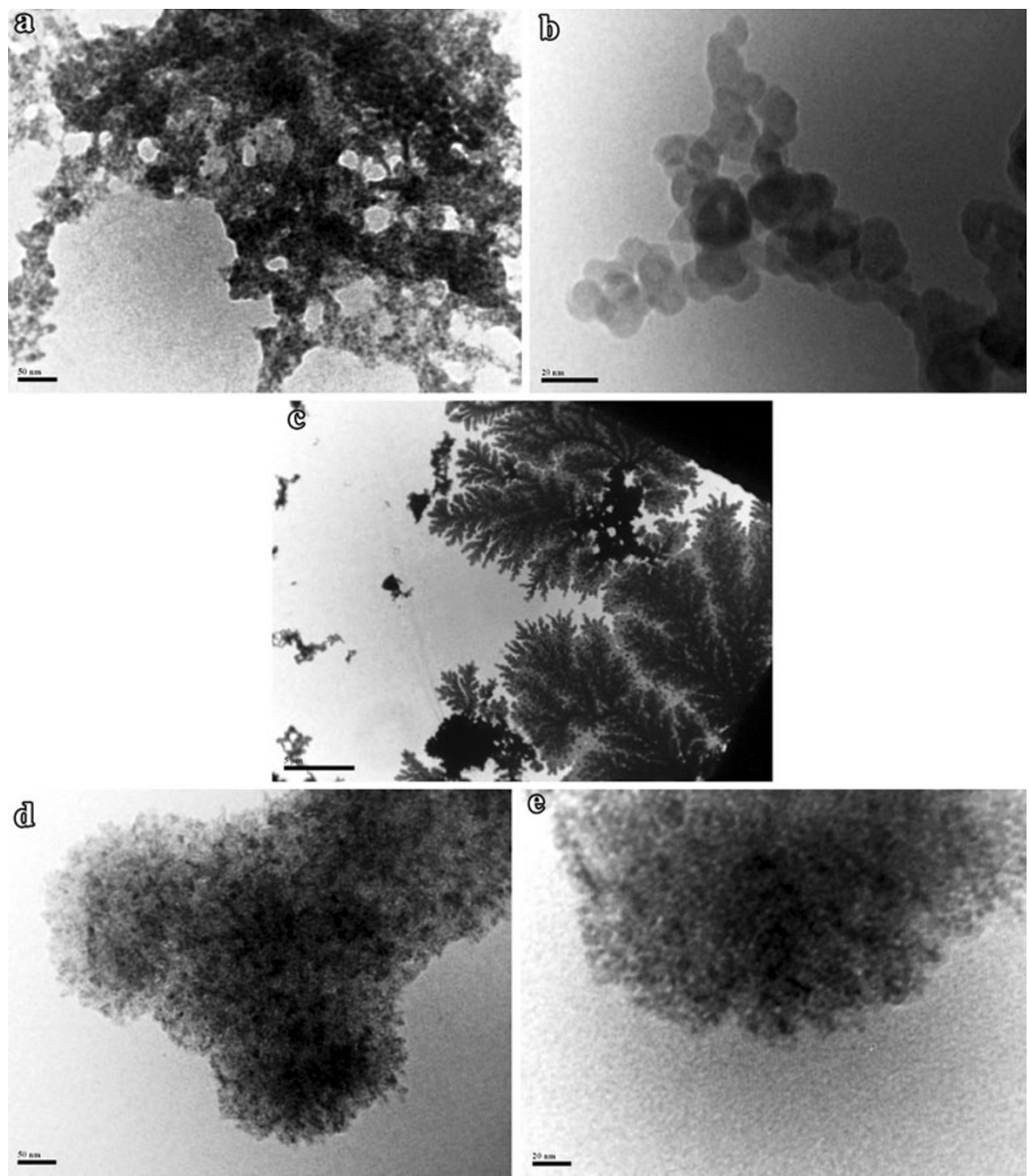

formed in square centimeter) signifies the improvement of growth rate without aggregation. In this work, the PMMA is not only used to control the particles size and also to modify the surface morphology by assembly of $\mathrm{ZnS}: \mathrm{Mn}^{2+}$ nanoparticles.

The TEM image of uncoated $\mathrm{ZnS}: \mathrm{Mn}^{2+} / \mathrm{ZnS}$ core-shell nanoparticles is seen in Fig. 3a. The core-shell nanoparticles show spherical morphology with a very narrow size distribution. After the growth of the $\mathrm{ZnS}$ shell, it shows (Fig. 3a) no difference with respect to $\mathrm{ZnS}: \mathrm{Mn}^{2+}$ nanoparticles except for their size. Due to the growth of the $\mathrm{ZnS}$ shell on $\mathrm{ZnS}: \mathrm{Mn}^{2+}$ nanoparticles, the average size $(5.5 \mathrm{~nm})$ of $\mathrm{ZnS}: \mathrm{Mn}^{2+} / \mathrm{ZnS}$ core-shell nanoparticles is larger than that $(4.2 \mathrm{~nm})$ of the $\mathrm{ZnS}: \mathrm{Mn}^{2+}$ core nanoparticles, which is clearly shown in the TEM image (Fig. 3a). This difference depicts that the shell thickness is around $1.3 \mathrm{~nm}$. The TEM result proves that the $\mathrm{ZnS}$ shell has been successfully coated on the surface of $\mathrm{ZnS}: \mathrm{Mn}^{2+}$ nanoparticles.
Moreover, the dispersion of nanoparticles has been noticeably improved with spherical morphology, which is due to the presence of $\mathrm{ZnS}$ shell on the $\mathrm{ZnS}: \mathrm{Mn}^{2+}$ nanoparticles. Figure $3 b-d$ represents the TEM images of PMMA capped $\mathrm{ZnS}: \mathrm{Mn}^{2+} / \mathrm{ZnS}$ core-shell nanoparticles with different magnifications. A pictorial representation of the model for growing the process of core-shell nanoparticles is shown in Fig. 4. The TEM images clearly confirm (Fig. 3b-d) the presence of $\mathrm{ZnS}$ shell on the $\mathrm{ZnS}: \mathrm{Mn}^{2+}$ nanoparticles.

The average size of the capped particle is significantly increased from $5.5\left(\mathrm{ZnS}: \mathrm{Mn}^{2+} / \mathrm{ZnS}\right)$ to $6.5 \mathrm{~nm}$, which may be due to the presence of small PMMA layer on $\mathrm{ZnS}: \mathrm{Mn}^{2+} / \mathrm{ZnS}$. As shown in Fig. 3b, c, the PMMA capped core-shell nanoparticles are well dispersed while comparing with uncapped particles, which may be due to the reduction of surface energy by $\mathrm{ZnS}$ shell as well as PMMA layer on $\mathrm{ZnS}: \mathrm{Mn}^{2+}$ surface simultaneously. Figure $3 \mathrm{c}$ shows the 
Fig. 3 TEM images of (ZnS: $\mathrm{Mn}^{2+} / \mathrm{ZnS}(\mathbf{a})$ and PMMA capped (b-d) $\mathrm{ZnS}: \mathrm{Mn}^{2+} / \mathrm{ZnS}$ core-shell nanoparticles with different magnifications
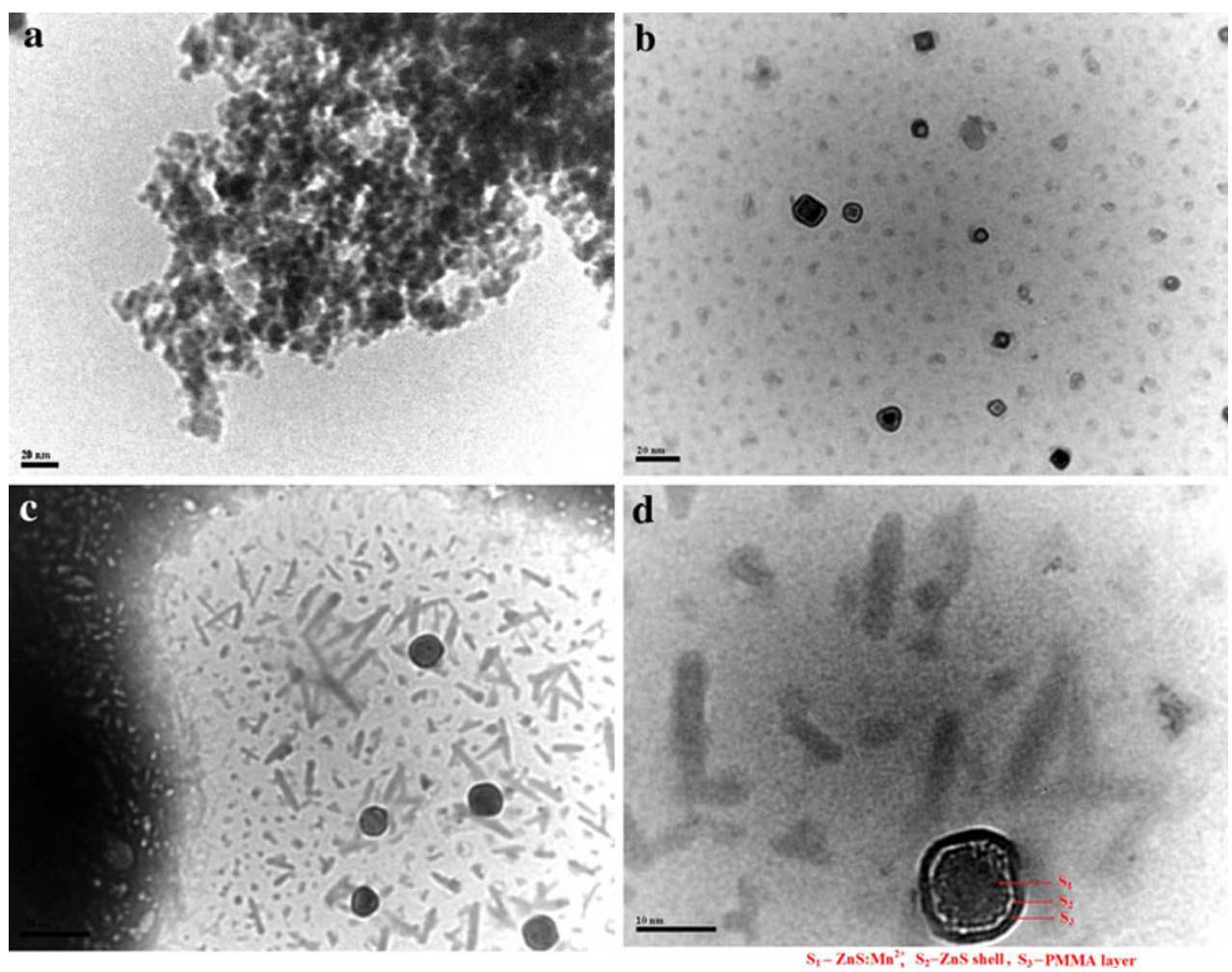

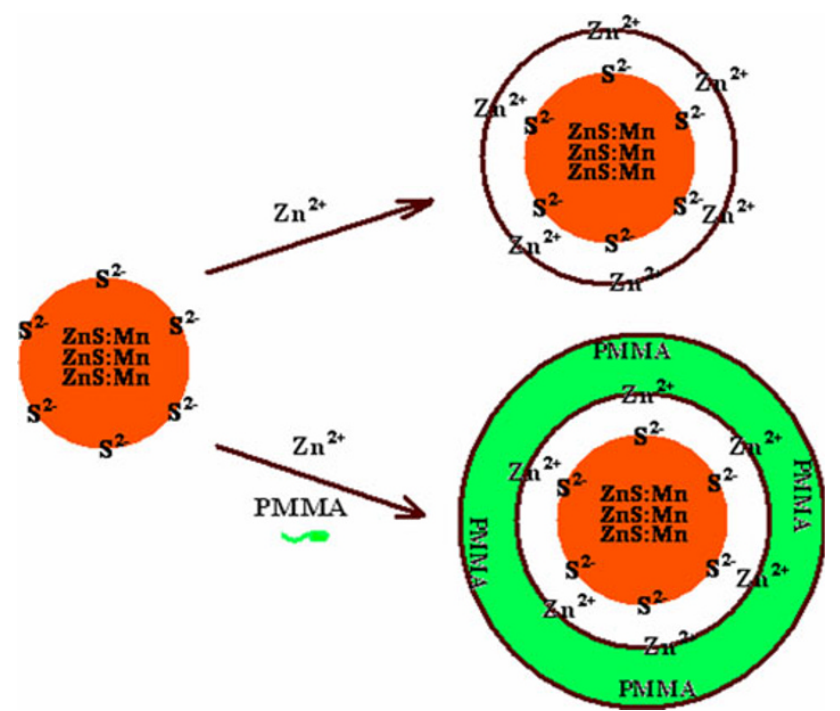

Fig. 4 A model diagram for the formation of $\mathrm{ZnS}: \mathrm{Mn}^{2+} \mathrm{ZnS}$ nanoparticles with and without PMMA

magnified image of a single $\mathrm{ZnS}: \mathrm{Mn}^{2+} / \mathrm{ZnS}$ core-shell particles capped with PMMA on the surface. It clearly indicates the presence of $\mathrm{ZnS}$ (white) as well as PMMA (dark) shells. In addition, Fig. 3c, d shows very small rodlike structure along with core-shell particles, which may be due to the presence of an excessive amount of PMMA in the solution.
Optical absorption

Figure 5 shows the UV-visible absorption (UV-vis) spectra of the nanoparticles. The absorption peaks are centered at around $300,280,314$, and $310 \mathrm{~nm}$ for $\mathrm{ZnS}: \mathrm{Mn}^{2+}, \mathrm{ZnS}: \mathrm{Mn}^{2+} / \mathrm{PMMA}, \mathrm{ZnS}: \mathrm{Mn}^{2+} / \mathrm{ZnS}$, and $\mathrm{ZnS}: \mathrm{Mn}^{2+} / \mathrm{ZnS} / \mathrm{PMMA}$ core-shell nanoparticles, respectively. The peak position reflects the band gap of the nanoparticles. Compared to $\mathrm{ZnS}: \mathrm{Mn}^{2+}$ nanoparticles, $\mathrm{ZnS}: \mathrm{Mn}^{2+} / \mathrm{ZnS}$ nanoparticles has significant red-shifted absorption peak. It may be due to reduction of the $\mathrm{ZnS}: \mathrm{Mn}^{2+} / \mathrm{ZnS}$ size. In addition, the absorption of all the samples is considerably blue-shifted from absorption (345 nm) of bulk $\mathrm{ZnS}$. This may be due to the quantum confinement effect (Bhargava and Gallagher 1994). In semiconductors, the confinement effects are strong for particles radius $(r)$ smaller than the exciton Bohr radius $\left(\mathrm{a}_{\mathrm{B}}\right),\left(r \ll \mathrm{a}_{\mathrm{B}}\right)$. Figure 6 exhibits the strong confinement for core-shell particles with radius less than $\sim 3 \mathrm{~nm}$. The calculated band gap is $4.14,4.44,3.95$, and $4.0 \mathrm{eV}$ for $\mathrm{ZnS}: \mathrm{Mn}^{2+}, \mathrm{ZnS}: \mathrm{Mn}^{2+} / \mathrm{PMMA}, \mathrm{ZnS}: \mathrm{Mn}^{2+} / \mathrm{ZnS}$, and $\mathrm{ZnS}: \mathrm{Mn}^{2+} / \mathrm{ZnS} / \mathrm{PMMA}$ core-shell nanoparticles, respectively.

The size dependence of the band gap for the nanoparticles has been calculated by a simple energy equation $(E=h v)$. From the band gap values, the sizes of the nanoparticles have been calculated by Brus model (Brus 1991). The calculated sizes of nanoparticles are furnished 


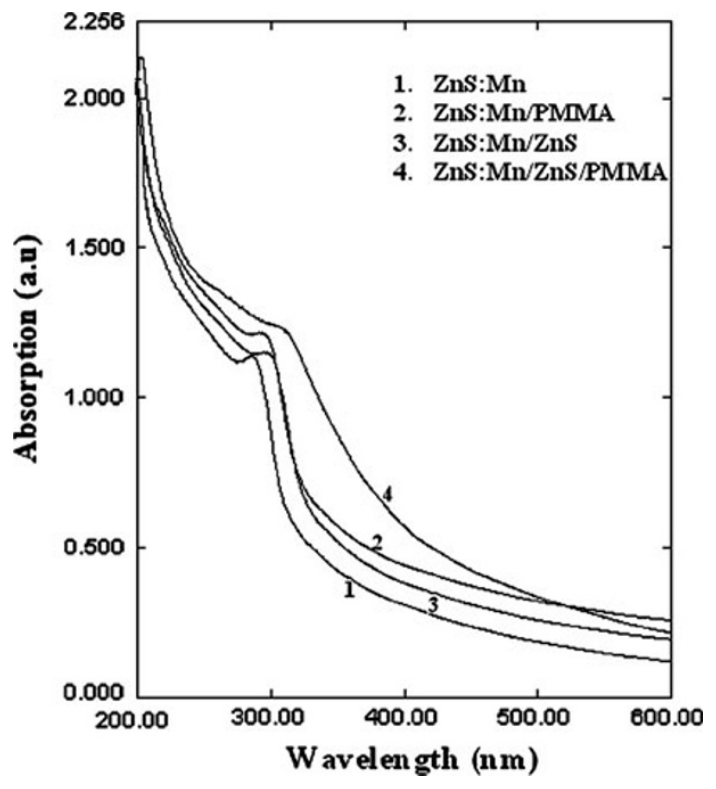

Fig. 5 UV-vis absorption spectra of uncapped and PMMA capped (ZnS: $\mathrm{Mn}^{2+}$ and $\mathrm{ZnS}: \mathrm{Mn}^{2+} / \mathrm{ZnS}$ ) nanoparticles

in Table 1, which agree well with the values obtained from both XRD and TEM analyses. The thickness of $\mathrm{ZnS}$ shell is also calculated and summarized in Table 1 .

\section{Photoluminescence study}

Figure 7 shows the room-temperature photoluminescence (PL) spectra of $\mathrm{ZnS}: \mathrm{Mn}^{2+}, \mathrm{ZnS}: \mathrm{Mn}^{2+} / \mathrm{PMMA}, \mathrm{ZnS}: \mathrm{Mn}^{2+}$ $\mathrm{ZnS}$ and $\mathrm{ZnS}: \mathrm{Mn}^{2+} / \mathrm{ZnS} / \mathrm{PMMA}$ core-shell nanoparticles. It was found that PL property of the uncoated $\mathrm{ZnS}: \mathrm{Mn}^{2+}$ nanoparticles is almost identical to that of the samples coated with $\mathrm{ZnS}$ shell. For all the samples, two emission peaks are dominated in the PL spectra. The first emission peak centered at $445 \mathrm{~nm}$ (blue), this emission peak should be certainly originated from the host $\mathrm{ZnS}$ but not from $\mathrm{Mn}$ ions. The second emission peak is centered at $588 \mathrm{~nm}$ (yellow-orange), which is due to ${ }^{4} T_{1} \rightarrow{ }^{6} A_{1}$ transition within the $3 d$ shell of Mn (Bhargava and Gallagher 1994).
As soon as $\mathrm{Mn}^{2+}$ is incorporated in $\mathrm{ZnS}$ lattice, the defectrelated emission decreases and $\mathrm{Mn}^{2+}$ emission increases, due to the energy transfer between $\mathrm{ZnS}$ host and $\mathrm{Mn}^{2+}$ impurity is more efficient. In addition, the intensity of defect-related emission strongly depends on the concentration of $\mathrm{Mn}^{2+}$ ions in the solution. The optimum concentration of $\mathrm{Mn}^{2+}$ (4\%) was selected in the previous work (Murugadoss et al. 2010). The PL emission of $\mathrm{ZnS}: \mathrm{Mn}^{2+}$ has been further improved by passivation of PMMA. This improvement may be due to reduction of surface defect by passivation of the carboxylic molecules. Moreover, Fig. 7 shows the PL spectrum of $\mathrm{ZnS}: \mathrm{Mn}^{2+}$ nanoparticles coated with $\mathrm{ZnS}$ shell. By the growth of an additional $\mathrm{ZnS}$ shell on $\mathrm{ZnS}: \mathrm{Mn}^{2+}$ nanoparticles, the emission intensity of $\mathrm{ZnS}: \mathrm{Mn}^{2+} / \mathrm{ZnS}$ core-shell nanoparticles were greatly enhanced due to elimination of surface defects (Wang et al. 2006). It was assumed that the elimination of the surface defect which reduce the non-radiative recombination path for the excitation energy in bare $\mathrm{ZnS}: \mathrm{Mn}^{2+}$, resulting the $\mathrm{Mn}^{2+}$ emission is enhanced as shown in the Fig. 7. The results probably revealed the presence of $\mathrm{ZnS}$ shell on $\mathrm{ZnS}: \mathrm{Mn}^{2+}$ surface. Further, the growth rate was extremely controlled by addition of PMMA on $\mathrm{ZnS}: \mathrm{Mn}^{2+} / \mathrm{ZnS}$ surface, resulting the emission intensity was decreased. These results are in good agreement with the XRD and TEM results.

\section{EPR Study}

The presence of $\mathrm{Mn}^{2+}$ ions in $\mathrm{ZnS}$ lattice and the growth of the $\mathrm{ZnS}$ on $\mathrm{ZnS}: \mathrm{Mn}^{2+}$ nanoparticles can be confirmed by EPR spectra. Figure 8a, b shows the EPR spectra of $\mathrm{ZnS}: \mathrm{Mn}^{2+}$ and $\mathrm{ZnS}: \mathrm{Mn}^{2+} / \mathrm{ZnS}$ core-shell nanoparticles, respectively. The six lines which appeared in the EPR spectra are attributed to $\left(\Delta M_{\mathrm{I}}=0\right.$ and $\left.\Delta M_{\mathrm{S}}= \pm 1\right)$ allowed transitions of the $\mathrm{Mn}^{2+}$ ions $(\mathrm{I}=5 / 2)$. For lower Mn concentrations, these lines are accompanied by smaller ones between them which are assigned to $\left(\Delta M_{\mathrm{I}}=0\right.$ and $\left.\Delta M_{\mathrm{S}}= \pm 1\right)$ forbidden transitions. The appearance of the well-resolved hyperfine structure together with the less
Fig. 6 Size dependence of the band gap of nanoparticles

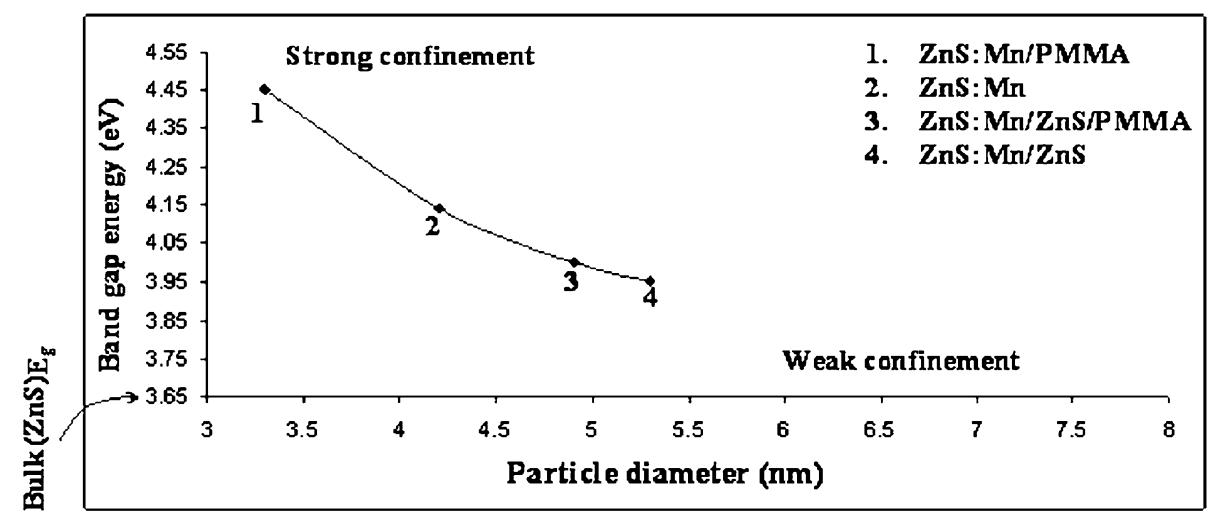


Table 1 Particle size, band gap, shell $(\mathrm{ZnS})$ and PMMA layer thickness as calculated from XRD, TEM and UV-Vis absorption analysis

\begin{tabular}{lllll}
\hline Sample & XRD $(\mathrm{nm})$ & TEM $(\mathrm{nm})$ & Band gap energy $(\mathrm{eV})$ & UV-Vis $(\mathrm{nm})$ \\
\hline ZnS:Mn & 4.2 & 4.2 & 4.14 & 4.2 \\
ZnS:Mn/PMMA & 3.2 & 3.3 & 4.45 & 3.3 \\
ZnS:Mn/ZnS & 5.4 & 5.5 & 3.95 & 5.3 \\
ZnS:Mn/ZnS/PMMA & 5.0 & 6.5 & 4.00 & 4.9 \\
ZnS shell thickness & 1.2 & 1.3 & - & 1.1 \\
PMMA layer thickness & - & 1.0 & - & - \\
\hline
\end{tabular}

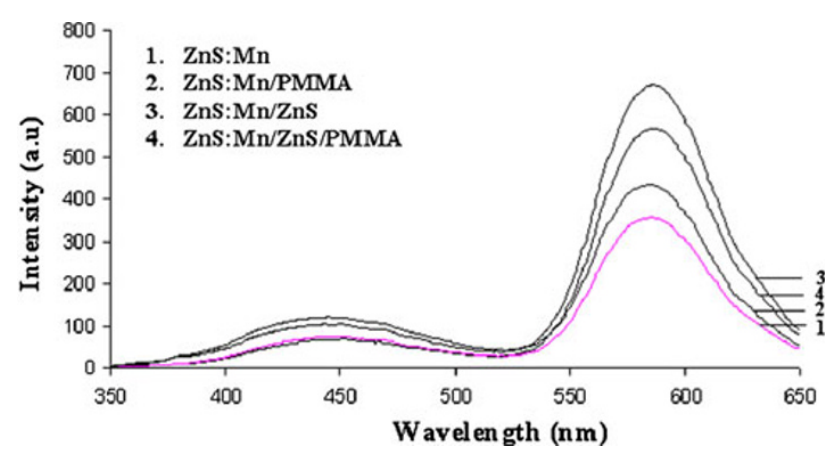

Fig. 7 PL spectra of uncapped and PMMA (0.5 g) capped $\left(\mathrm{ZnS}: \mathrm{Mn}^{2+}(4 \%)\right.$ and $\left.\mathrm{ZnS}: \mathrm{Mn}^{2+} / \mathrm{ZnS}(\mathrm{Zn} 0.1 \mathrm{M})\right)$ nanoparticles

intense lines between them (at approximately $g=2$ ) proves that many $\mathrm{Mn}$ ions are at nearly cubic symmetry (Sooklal et al. 1996; Hoffman et al. 1998). Both EPR spectra consist of a broad curve and the six lines of sharp splitting. The broad curve is caused by the electron spinspin interactions $(1 / 2 \rightarrow-1 / 2)$ of the isolated $\mathrm{Mn}^{2+}$ ions in the $\mathrm{ZnS}: \mathrm{Mn}^{2+}$ nanoparticles, in which a symmetric Lorentzian line of the broad curve is observed since the sample size is smaller than the skin depth (Ji et al. 2003). The six lines are due to the hyperfine interaction with the Mn nuclear spin $(I=5 / 2)$, which indicate that the $\mathrm{Mn}^{2+}$ ions have entered the $\mathrm{ZnS}$ host lattices (Norris et al. 2001). This hyperfine structure shows the electron spin-nuclear spin interactions in an isolated $\mathrm{Mn}^{2+}$ ion. As the $\mathrm{Mn}^{2+}$ ion is affected by other $\mathrm{Mn}^{2+}$ ions that are randomly distributed around it, the $\mathrm{Mn}-\mathrm{Mn}$ interactions should result in a reduction of the electron spin-nuclear spin interactions in an individual $\mathrm{Mn}$ ion ( $\mathrm{Ji}$ et al. 2003). This phenomenon is observed after the formation of the $\mathrm{ZnS}$ shell on the $\mathrm{ZnS}: \mathrm{Mn}^{2+}$ nanoparticles. The signals from the EPR spectrum of the $\mathrm{ZnS}: \mathrm{Mn}^{2+}$ (Fig. 8a) nanoparticles show six well-resolved peaks, while $\mathrm{ZnS}: \mathrm{Mn}^{2+} / \mathrm{ZnS}$ core-shell (Fig. 8b) nanoparticles show poorly resolved six line structure because some $\mathrm{Mn}^{2+}$ ions near the surface of $\mathrm{ZnS}: \mathrm{Mn}^{2+}$ are shielded by an additional $\mathrm{ZnS}$ shell layers (Kennedy et al. 1995). In addition, the results of EPR spectra were in fairly agreement with those of luminescence spectra (Fig. 8). The substitution of $\mathrm{Mn}^{2+}$ at $\mathrm{Zn}^{2+}$ sites is further confirmed from the XRD data where an increase in unit cell volume is observed for $\mathrm{Mn}^{2+}$ ion substituted sample.

Thermal study

Annealing process is effective for reproducible size control of nanoparticles and also it can be used to improve the
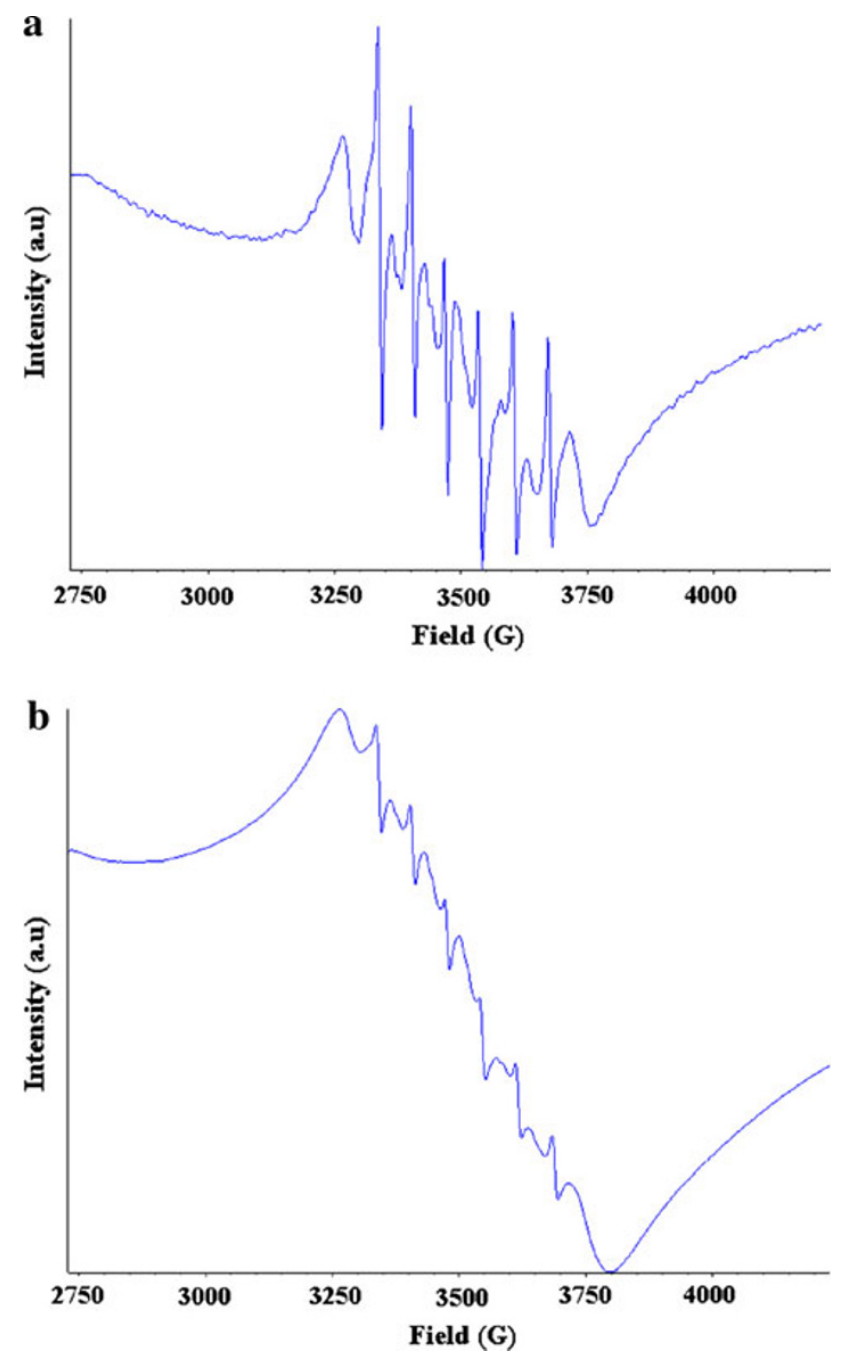

Fig. 8 EPR spectra of $\mathrm{ZnS}: \mathrm{Mn}^{2+}$ (a) and $\mathrm{ZnS}: \mathrm{Mn}^{2+} / \mathrm{ZnS}$ (b) nanoparticles 


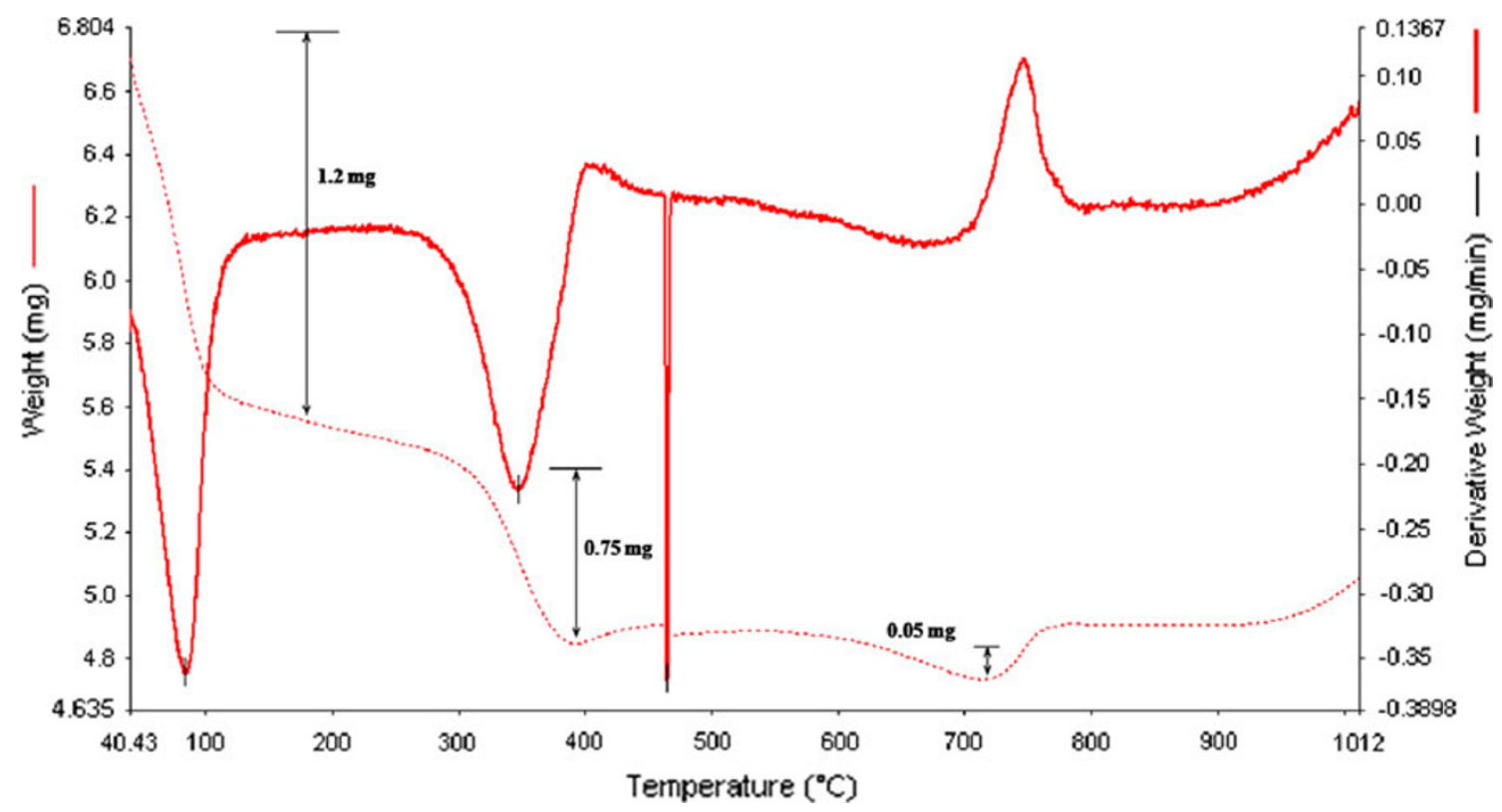

Fig. 9 TG-DTA curve of $\mathrm{ZnS}: \mathrm{Mn}^{2+} / \mathrm{ZnS}$ nanoparticles

crystal quality and stability which are required for device purposes. The thermogravimetric and differential thermal analysis (TG-DTA) were studied for $\mathrm{ZnS}: \mathrm{Mn}^{2+} / \mathrm{ZnS}$ nanoparticles in the temperature ranges from room temperature (RT) to $1,000{ }^{\circ} \mathrm{C}$ which was increased by $10{ }^{\circ} \mathrm{C} / \mathrm{min}$ in an air atmosphere. Figure 9 shows combined plots of TG and DTA. The TGA curve of $\mathrm{ZnS}: \mathrm{Mn}^{2+} / \mathrm{ZnS}$ nanoparticles reveals, about $2 \mathrm{mg}$ of the total weight loss is reserved. From, the TGA data plots, it is noticed that the weight loss of the nanoparticles were found to take place up to $700{ }^{\circ} \mathrm{C}$. In DTA curve, a large endothermic peak was observed from 45 to $100{ }^{\circ} \mathrm{C}$. The broadened endothermic peak corresponding to a noticeable fall in specimen weight $(1.2 \mathrm{mg}$ ) over the same temperature range is attributed to the elimination of water from sample. The second endothermic peak covers the temperature range $290-360{ }^{\circ} \mathrm{C}$ with significant weight loss of $0.75 \mathrm{mg}$, which may be due to the decomposition of sulfur and Mn released from the $\mathrm{ZnS}$ matrix. Another very sharp endothermic peak was observed around $460{ }^{\circ} \mathrm{C}$, and it was believed to be the beginning of the phase transition. At $720{ }^{\circ} \mathrm{C}$, much smaller weight loss $(0.05 \mathrm{mg})$ is observed, which may be due to simultaneous release of sulfur and oxidation of sample. Finally, a broad exothermic peak was observed around $750{ }^{\circ} \mathrm{C}$, implying improvement of the crystalline nature of the obtained sample. Moreover, in this stage instead of weight loss, a significant amount of weight was gained. This may be due to adsorption of the oxygen molecules from the air atmosphere (Murugadoss 2011). Above $750{ }^{\circ} \mathrm{C}$, there is no change in TGA curve up to $1,000{ }^{\circ} \mathrm{C}$. It may be due to completion of the processes of removed residual sulfur ions and oxidation of $\mathrm{ZnS}$ into $\mathrm{ZnO}$ (Murugadoss 2011).

\section{Conclusions}

In summary, Mn (4\%) doped $\mathrm{ZnS}$ nanoparticles have been successfully coated with $\mathrm{ZnS}\left(\mathrm{ZnS}: \mathrm{Mn}^{2+} / \mathrm{ZnS}\right)$ and capped with PMMA on the ( $\left.\mathrm{ZnS}: \mathrm{Mn}^{2+} / \mathrm{ZnS} / \mathrm{PMMA}\right)$ surface. The high-quality $\mathrm{ZnS}: \mathrm{Mn}^{2+} / \mathrm{ZnS}$ core-shell nanoparticles were synthesized in an air atmosphere. The size of $\mathrm{ZnS}: \mathrm{Mn}^{2+}$ particles in the composite decreased as compared to bare $\mathrm{ZnS}: \mathrm{Mn}^{2+}$ particles which suggest the restriction in the growth of particles by the $\mathrm{ZnS}$ shell. Addition of PMMA, further decreased the size of $\mathrm{ZnS}: \mathrm{Mn}^{2+}$ and $\mathrm{ZnS}: \mathrm{Mn}^{2+}$, $\mathrm{ZnS}$ nanoparticles suggesting its role as a capping agent. The obtained core-shell particles are highly crystalline and nearly monodisperse with particles size of 3-6 nm range. On the basis of oxidation of the $\mathrm{ZnS}$ nanoparticle, pure well-crystallized $\mathrm{ZnO}$ nanopowders were obtained from $\mathrm{ZnS}: \mathrm{Mn}^{2+} / \mathrm{ZnS}$ by heat treatment. The water-soluble and monodisperse $\mathrm{ZnS}: \mathrm{Mn}^{2+} / \mathrm{ZnS}$ nanoparticles show an improved fluorescence property, indicating their potential applications in biological labeling and active component in optoelectronic devices.

Acknowledgments The author would like to acknowledge the service rendered by scientific officers of IIT Bombay, Mumbai, CECRI, Karaikudi, STIC, Cochin and CISL, Annamalai University, for recording TEM, XRD, TG-DTA, and FT-IR spectra. The author also likes to thank Dr. N. Rajendran, Department of Chemistry, Annamalai University, India, for providing UV-visible and PL facility. 
Open Access This article is distributed under the terms of the Creative Commons Attribution License which permits any use, distribution, and reproduction in any medium, provided the original author(s) and the source are credited.

\section{References}

Bhargava RN, Gallagher D (1994) Optical properties of manganesedoped nanocrystals of ZnS. Phys Rev Lett 72:416-419

Brus L (1991) Quantum crystallites and nonlinear optics. Appl Phys A 53:465-474

Cao LX, Zhang JH, Ren SL, Huang SH (2002) Luminescence enhancement of core-shell $\mathrm{ZnS}: \mathrm{Mn} / \mathrm{ZnS}$ nanoparticles. Appl Phys Lett 80:4300-4302

Cao J, Yang JH, Zhang YJ, Yang LL, Wang YX, Wei MB, Liu Y, Gao M, Liu XY, Xie Z (2009) Optimized doping concentration of manganese in zinc sulfide nanoparticles for yellow-orange light emission. J Alloys Compd 486:890-894

Cullity BD (1978) Elements of X-ray diffraction. Addison-Wesley, Reading

Deka S, Quarta A, Lupo MG, Falqui A, Boninelli S, Giannini C, Morello G, Giorgi MD, Lanzani G, Spinella C, Cingolani R, Pellegrino T, Manna L (2009) CdSe/CdS/ZnS double shell nanorods with high photoluminescence efficiency and their exploitation as biolabeling probes. J Am Chem Soc 131:2948-2958

Hajisalem G, Marandi M, Taghavinia N (2009) The two-step thermochemical growth of $\mathrm{ZnS}: \mathrm{Mn}$ nanocrystals and a study of luminescence evolution. Nanotechnology 20:95706

Hoener CF, Allan KA, Bard AJ (1992) Demonstration of a shell-core structure in layered cadmium selenide-zinc selenide small particles by X-ray photoelectron and Auger spectroscopies. J Phys Chem 96:3812-3817

Hoffman DM, Hofstaetter A, Lei U, Meyer BK, Gounio G (1998) EPR and ENDOR investigations on CdS: Mn nanocrystals. J Cryst Growth 184(185):383-387

Ipe BI, Niemeyer CM (2006) Nanohybrids composed of quantum dots and cytochrome P450 as photocatalysts. Angew Chem Int Ed 45:504-507

Ji TH, Jain WB, Fang JY (2003) The first synthesis of $\mathrm{Pb}_{1-x} \mathrm{Mn}_{x} \mathrm{Se}$ nanocrystals. J Am Chem Soc 125:8448-8449

Jian WP, Zhuang JQ, Yang WS, Bai YB (2007) Improved photoluminescence of $\mathrm{ZnS}: \mathrm{Mn}$ nanocrystals by microwave assisted growth of $\mathrm{ZnS}$ shell. J Lumin 126:735-740

Jiang DX, Cao LX, Su G, Liu W, Qu H, Sun YG, Dong BH (2007) Luminescence enhancement of Mn doped $\mathrm{ZnS}$ nanocrystals passivated with zinc hydroxide. Appl Surf Sci 253:9330-9335

Jiang DX, Cao LX, Su G, Liu W, Qu H, Sun YG, Dong BH (2008) Synthesis and luminescence properties of core/shell $\mathrm{ZnS}: \mathrm{Mn} /$ $\mathrm{ZnO}$ nanoparticles. Nanoscale Res Lett 4:78-83

Jiang DX, Cao LX, Su G, Liu W, Qu H, Sun YG, Dong BH (2009) Shell thickness dependence of luminescence intensity in core/ shell ZnS:Mn/ZnS nanoparticles. Mater Chem Phys 115: 795-798

Kennedy TA, Glaser ER, Klein PB, Bhargava RN (1995) Symmetry and electronic structure of the Mn impurity in $\mathrm{ZnS}$ nanocrystals. Phys Rev B 52:R14356-R14359
Keshari AK, Pandey AC (2009) Highly stabilized and photoluminescence enhancement of $\mathrm{ZnS}: \mathrm{Mn}^{2+}$ nanoparticles in biotin matrix. J Appl Phys 105:64315

Kim JY, Osterloh FE (2005) ZnO-CdSe nanoparticle clusters as directional photoemitters with tunable wavelength. J Am Chem Soc 127:10152-10153

Kortan AR, Hull R, Opila RL, Bawendi MG, Steigerxald ML, Caroll P, Brus LE (1990) Nucleation and growth of cadmium selenide on zinc sulfide quantum crystallite seeds, and vice versa, in inverse micelle media. J Am Chem Soc 112:1327-1332

Lu CH, Bhattacharjee B, Chen SY (2009) Microwave synthesis of manganese-ion-doped zinc sulfide nano-phosphors using a novel monomer. J Alloys Compd 475:116-121

Mews A, EychmuÈller A, Giezrsig M, Schooss D, Weller HJ (1994) Preparation, characterization, and photophysics of the quantum dot quantum well system cadmium sulfide/mercury sulfide/ cadmium sulfide. J Phys Chem 98:934-941

Murugadoss G (2011) Synthesis, optical, structural and thermal characterization of $\mathrm{Mn}^{2+}$ doped $\mathrm{ZnS}$ nanoparticles using reverse micelle method. J Lumin 131:2216-2223

Murugadoss G, Rajamannan B, Ramasamy V (2010) Synthesis, characterization and optical properties of water-soluble ZnS: $\mathrm{Mn}^{2+}$ nanoparticles. J Lumin 130:2032-2039

Nien YT, Hwang KH, Chen IG, Yu K (2008) Photoluminescence enhancement of $\mathrm{ZnS}: \mathrm{Mn}$ nanoparticles by $\mathrm{SiO}_{2}$ coating. J Alloys Compd 455:519-523

Norris DJ, Yao N, Charnock FT, Kennedy TA (2001) High-quality manganese-doped ZnSe nanocrystals. Nano Lett 1:3-7

Ouyang L, Maher KN, Yu CL, McCarty J, Park H (2007) Catalystassisted solution-liquid-solid synthesis of $\mathrm{CdS} / \mathrm{CdSe}$ nanorod heterostructures. J Am Chem Soc 129:133-138

Santra S, Yang H, Holloway PH, Stanley JT, Mericle RA (2005) Synthesis of water-dispersible fluorescent, radio-opaque, and paramagnetic CdS:Mn/ZnS quantum dots: a multifunctional probe for bioimaging. J Am Chem Soc 127:1656-1657

Sooklal K, Cullum BS, Angel S, Murphy CJ (1996) Photophysical properties of $\mathrm{ZnS}$ nanoclusters with spatially localized $\mathrm{Mn}^{2+}$. J Phys Chem 100:4551-4555

Tian Y, Newton T, Kotov NA, Guldi DM, Fendler JH (1996) Coupled composite CdS-CdSe and core-shell types of $(\mathrm{CdS}) \mathrm{CdSe}$ and (CdSe)CdS nanoparticles. J Phys Chem 100:8927-8939

Wang ZL, Quan ZW, Jia PY, Lin CK, Luo Y, Chen Y, Fang J, Zhou W, O'Connor CJ, Lin J (2006) A facile synthesis and photoluminescent properties of redispersible $\mathrm{CeF}_{3}, \mathrm{CeF}_{3}: \mathrm{Tb}^{3+}$, and $\mathrm{CeF}_{3}: \mathrm{Tb}^{3+} / \mathrm{LaF}_{3}$ (core/shell) nanoparticles. Chem Mater 18: 2030-2037

Wang X, Xu J, Chen H (2008) A new electrochemiluminescence emission of $\mathrm{Mn}^{2+}$-doped $\mathrm{ZnS}$ nanocrystals in aqueous solution. J Phys Chem C 112:17581-17585

Xiao Q, Xiao C (2008) Synthesis and photoluminescence of watersoluble $\mathrm{Mn}: \mathrm{ZnS} / \mathrm{ZnS}$ core/shell quantum dots using nucleationdoping strategy. Optic Mater 31:455-460

Yang Y, Chen O, Angerhofer A, Cao YC (2006) Radial-positioncontrolled doping in $\mathrm{CdS} / \mathrm{ZnS}$ core/shell nanocrystals. J Am Chem Soc 128:12428-12429

Zhuang JQ, Zhang XD, Wang G (2003) Synthesis of water-soluble $\mathrm{ZnS}: \mathrm{Mn}^{2+}$ nanocrystals by using mercaptopropionic acid as stabilizer. J Mater Chem 13:1853-1857 